\title{
Effects of Fertilizer Application and Dry/Wet Processing of Miscanthus x giganteus on Bioethanol Production
}

Nana Abayie Boakye-Boaten ${ }^{\mathrm{a}, \mathrm{b}}$, Shuangning Xiu ${ }^{\mathrm{b}, *}$, Abolghasem Shahbazi $^{\mathrm{b}}$, Lijun Wang ${ }^{\mathrm{b}}$, Rui Li ${ }^{\mathrm{c}, \mathrm{b}}$, Michelle Mims ${ }^{\mathrm{b}}$, Keith Schimmel ${ }^{\mathrm{a}}$

${ }^{a}$ Energy and Environmental Systems Program, College of Arts and Science, North

Carolina A \& T State University, 1601 East Market Street, Greensboro, NC 27411, United States

${ }^{\mathrm{b}}$ Biological Engineering Program, Department of Natural Resources and Environmental Design, North Carolina A \& T State University, 1601 East Market Street, Greensboro, NC 27411, United States

c Joint School of Nanoscience and Nanoengineering, North Carolina A \& T State University, 2907 E. Gate City Blvd, Greensboro, NC 27401, United States ${ }^{1}$

\section{ABSTRACT}

The effects of wet and dry processing of miscanthus on bioethanol production using simultaneous saccharification and fermentation (SSF) process were investigated, with wet samples showing higher ethanol yields than dry samples. Miscanthus grown with no fertilizer, with fertilizer and with swine manure were sampled for analysis. Wetfractionation was used to separate miscanthus into solid and liquid fractions. Dilute sulfuric acid pretreatment was employed and the SSF process was performed with

Corresponding author. Tel.:+1 336-334-7787; fax:+1 336-334-7270

E-mail address: xshuangn@ncat.edu (S. Xiu) 
saccharomyces cerevisiae and a cocktail of enzymes at $35{ }^{\circ} \mathrm{C}$. After pretreatment, cellulose compositions of biomass of the wet samples increased from $61.0-67.0 \%$ to $77.0-87.0 \%$, which were higher than the compositions of dry samples. The highest theoretical ethanol yield of $88.0 \%$ was realized for wet processed pretreated miscanthus, grown with swine manure. Changes to the morphology and chemical composition of the biomass samples after pretreatment, such as crystallinity reduction, were observed using SEM and FTIR. These changes improved ethanol production.

Keywords:

Wet and dry processing

Miscanthus x giganteus (MxG)

Dilute sulfuric acid pretreatment

Simultaneous Saccharification and Fermentation

Bioethanol 


\section{Introduction}

Fuel ethanol is a major product from the biorefining process, and has been produced commercially in several countries in the world for more than two decades as an alternative fuel (Nghiem et al., 2011). Even though nowadays corn and sugar cane are still the most widely used feedstocks for commercial production of ethanol, lignocellulosic biomass feedstocks (e.g. Miscanthus x giganteus) are considered the ultimate feedstocks for ethanol production (Nghiem et al., 2011). Factors such as high yields of dry matter and the ability to grow under diverse climates and on marginal lands, are some of the features of giant miscanthus that have been touted as making the plant ideal for bioenergy purposes (Kärcher et al., 2015). However, giant miscanthus for bioenergy is a relatively new crop and a new subject of research in the United States. As such, it will take some time to determine how it will react to fertilization on various soil types. Nevertheless, some studies have already shown that perennial miscanthus requires relatively fewer fertilizer inputs to sustain growth compared to other annual $\mathrm{C}_{4}$ grass crops (Christian et al., 2008).

The economic competitiveness of the ethanol production process depends strongly on the amount of heat and power used (Pfeffer et al., 2007). Both starch-based and carbohydrate materials, such as sorghum grain, corn, and municipal solid waste (MSW) normally require the use of an external energy source in the conventional ethanol production process (Ferrari et al., 2013). However, an energy balance can only be considered favorable if the energy needed to produce a biofuel unit is lower than the energy exiting the system (Ferrari et al., 2013). It is imperative to evaluate what kind of 
energy is being used and also minimize energy usage to make the process more energy efficient.

An important step in the bioethanol production process is sample preparation. Of first and second-generation feedstock that has high moisture content, drying of the materials before fermentation is a conventional practice in the industry. Fennel and Boldor (2014) identified increased transportation costs and biomass losses during long-term storage as some of the reasons for drying the biomass before fermentation. Even though efficiencies of fermentation processes are already fairly high (Fennell and Boldor, 2014), it is important to improve the energy efficiency of the ethanol production processes within the context of a biorefinery platform by developing innovations that allow for the use of lignocellulosic biomass materials that do not have to undergo physical/ thermal processing such as drying. It is important to note that second-generation ethanol production has not yet reached commercial maturity and requires the investigation of different process configurations to develop efficient conversion processes to speed up commercialization (Silva Ortiz and de Oliveira Jr., 2014).

Moreover, for commercialization purposes, it is important to also consider the issue of water balance in the ethanol production process, as distillation (dewatering) is also a high-energy consumption step in the process, with energy consumption increasing as the water to be removed increases, which can be due to high moisture content in the feedstock (Ferrari et al., 2013). One way to attain energy savings on distillation is to achieve high ethanol concentrations from the fermentation process, such as high gravity fermentation, where the initial fermentable sugar concentration is high (Bai et al., 2008). Therefore, there 
is a need to develop an innovative approach to improve the energy efficiency of the process and maximize ethanol yield.

Bioethanol production based on dry processing of biomass has been addressed by a number of researchers. Fennell and Boldor (2014) examined continuous microwave drying of sweet sorghum bagasse biomass for ethanol production, and found that the drying rate for microwave drying was significantly higher than conventional drying (Fennell and Boldor, 2014). An energy evaluation of drying sweet potato for ethanol production has also been performed (Ferrari et al., 2013). This study concluded generally, that the energy consumption was greater than the energetic content of the bioethanol produced when drying sweet potato biomass was involved in the process (Ferrari et al., 2013). Scordia et al. (2013) dried giant miscanthus $\left(65^{\circ} \mathrm{C} \pm 5^{\circ} \mathrm{C}\right)$ and milled it to a particle size smaller than $2 \mathrm{~cm}$ for their assessment on the effect of oxalic acid pretreatment of miscanthus biomass for ethanol production. This was done even though the moisture content at the time of harvest was only 15\% (Scordia et al., 2013). Similarly, wheat straw (Saha et al., 2015), miscanthus (Cha et al., 2015), rapeseed straw (Choi et al., 2013) and elephant grass (Eliana et al., 2014), have all been subjects of recent studies which examined drying at various temperatures, milling and using for the production of ethanol through a simultaneous saccharification and fermentation process.

Although quite a number of studies have been conducted on dry processing of biomass for ethanol production using miscanthus as a feedstock, bioethanol production from wet miscanthus has not been examined thus far. Furthermore, these studies did not take into account how fertilizer (organic/inorganic) application to soils during miscanthus 
cultivation affected ethanol yields and concentrations. Therefore, the overall goal of this research was to evaluate the feasibility of ethanol production from miscanthus grown with different fertilizer treatments via wet processing. A comparison of ethanol yields and concentrations from dry and wet processed biomass will help to determine the effectiveness of the wet processing of miscanthus in bioethanol production. The ability to produce a high concentration of ethanol and a high theoretical ethanol yield, without drying the biomass will undoubtedly improve the energy efficiency of the process, a desirable outcome for commercial considerations.

\section{Materials and Methods}

\subsection{Materials}

Miscanthus was harvested from the North Carolina A \& T State University Farm in Greensboro during July, 2015, using a Tanaka TPH 270s-pole hedge trimmer for consistent cuts. Miscanthus grown with two fertilizer treatments of NPK 17-17-17 (T1: 0 lbs/ac and T5: $280 \mathrm{lbs} / \mathrm{ac}$ ) and swine manure (Tsw: $1000 \mathrm{lbs} / \mathrm{ac}$ ) were used for the study. Swine manure is applied on agricultural soils as fertilizer, since it contributes to increased organic matter $(\mathrm{OM})$ in soil and is active in the provision of plant nutrients (Segat et al., 2015). Commercial enzymes, cellulase (Novozymes, NS 50013), $\beta$-glucosidase (Novozymes, NS 50010), and hemicellulase (Novozymes, NS 22002) were supplied by Novozymes North America Inc. (Franklinton, North Carolina) and were used as soon as they were received. Saccharomyces cerevisiae (ATCC 24858) was purchased from American Type Culture Collection (ATCC) (Manassas, VA) for fermentation processes. 


\subsection{Sample preparation}

Freshly harvested miscanthus was shredded using a DR wood chipper/shredder (14.50 Pro Manual Start, DR Power Equipment, Vergennes, Vermont), bagged, sealed and stored at $4^{\circ} \mathrm{C}$. Harvested biomass was pressed and separated into juice and solid cake, using a Carver laboratory press (\#2094 cage equipment, Carver Inc., Wabash, IN) at an optimized force of 30,000 lbs for $15 \mathrm{~min}$. The green juice was stored in a freezer for use in further downstream processes as part of a biorefinery platform. The pressed solid cake was divided into two portions; one taken through a dry processing method and the second, a wet processing method.

\subsubsection{Dry processing method}

The miscanthus biomass was dried in an isotemp oven (Fisher Scientific, USA) at a temperature of $105{ }^{\circ} \mathrm{C}$ for a period of 24 hours, thereby completely removing any moisture from the solid cake. Using a rotary knife mill (Thomas Model 4 Wiley mill, Thomas Scientific, Swedesboro, NJ) the dried miscanthus was ground to particle sizes between 0.3 and $0.6 \mathrm{~mm}$ for further analyses and downstream processing.

\subsubsection{Wet processing method}

$100 \mathrm{~g}$ of deionized water was added to $50 \mathrm{~g}$ of the pressed miscanthus solid cake and thoroughly mixed together. This 2:1 (water: miscanthus) cake was then homogenized using a knife mill Grindomix GM $200\left(\right.$ Retsch $^{\circledR}$, Verder Scientific Inc. Newtown, PA) at a speed of 9000 RPM for $2 \mathrm{~min}$. Subsequently, the slurry was separated into solid and liquid 
fractions using a centrifuge (Centra-GP8R Centrifuge, ThermoIEC) at a rotational speed of $2600 \mathrm{RCF}$ for $10 \mathrm{~min}$ at room temperature. The solid cake was stored in sealable containers at $-4{ }^{\circ} \mathrm{C}$ for further analysis and downstream processing.

\subsection{Biomass analytical procedures}

Compositional analysis of the biomass was done using the laboratory analytical procedures (LAPs) of the National Renewable Energy Laboratory (NREL). The moisture content of the biomass was determined by the LAP \#001 method. The ash content analysis of the biomass was performed by the LAP \#005 method (Sluiter et al., 2008). Structural analyses were carried out using LAP \#003 for acid-insoluble lignin and the determination of carbohydrates in biomass using HPLC (Sluiter et al., 2011).

\subsection{Dilute sulfuric acid pretreatment (DSAP)}

DSAP was done using a Dionex ASE 350 Accelerated Solvent Extractor (Dionex Corporation, Sunnyvale, C.A). The biomass was pretreated using a $1 \%$ (v/v) sulfuric acid solution, at a pretreatment temperature of $160^{\circ} \mathrm{C}$ for $10 \mathrm{~min}$. About $10 \mathrm{~g}$ (dry process) or $30 \mathrm{~g}$ (wet process) of ground/blended miscanthus was placed into each of the appropriate number of tared $66 \mathrm{~mL}$ Dionex extraction cells containing a glass fiber filter. The appropriate number of $150 \mathrm{~mL}$ collection vials were weighed and placed onto the ASE system. The extractor passed $60 \mathrm{~mL}$ of dilute sulfuric acid solution into each cell containing the biomass. The cells were heated to the desired temperature $\left(160{ }^{\circ} \mathrm{C}\right)$ at a heating rate of $25^{\circ} \mathrm{C} / \mathrm{min}$, with the temperature maintained at that temperature for $15 \mathrm{~min}$. 
After this treatment, $40 \mathrm{~mL}$ of the dilute sulfuric acid solution was passed into the cells to rinse the biomass, bringing the total volume of solution used to about $100 \mathrm{~mL}$. The extraction cells were allowed to cool to $25{ }^{\circ} \mathrm{C}$ by sitting at room temperature for $30 \mathrm{~min}$. The recovered biomass samples were stored in sealable containers and kept at $-4{ }^{\circ} \mathrm{C}$ for further downstream processing and analyses such as compositional analysis and fermentation.

\subsection{Scanning electron microscopy (SEM)}

The morphological images of the DSAP biomass were taken and compared to the images of the untreated biomass by digitally observing these samples with a Carl Zeiss Auriga Bu FIB field emission scanning electron microscope (FESEM). Thin layers of the samples were first mounted on copper sample holders using copper tapes, and coated with palladium/gold before being digitally observed.

\subsection{Fourier-transform infrared spectroscopy (FTIR)}

The structural constituents and chemical functional groups of the untreated and pretreated miscanthus samples were analyzed using a Shimadzu IR Prestige-21 Fourier transform infrared (FTIR) spectrophotometer, equipped with accessories capable of performing attenuated total reflection (ATR) or sample/KBr mixture analysis. Using the latter approach, the biomass samples were finely powdered to reduce scattering losses and absorption band distortions, and mixed with $\mathrm{KBr}$ at a sample/KBr weight ratio of 1:100. The

mixtures were manually ground using a mortar and pestle, then pressed to generate 
translucent pelletized disc samples. The pelletized disc samples were placed in the path of the IR light, where spectra were collected over 64 scans of the sample in the range of 4000 $\mathrm{cm}^{-1}-400 \mathrm{~cm}^{-1}$ at a resolution of $4 \mathrm{~cm}^{-1}$. The Happ-Genzel apodization function was used to achieve a good balance between ripple size and resolution.

\subsection{Simultaneous saccharification and fermentation (SSF)}

A pretreated biomass loading of $5 \mathrm{~g}$ (wet basis) for both the dry and wet processed biomass, with a total working volume of $50 \mathrm{~mL}$ and a $\mathrm{pH}$ adjusted to 4.5 by the addition of 0.05 M citric buffer was employed for the fermentation. Wheaton septum glass bottles $(125 \mathrm{~mL})$ were used as the reaction vessels. Enzymatic hydrolysis was achieved by the addition of a cocktail of enzymes, including cellulase (Novozyme NS50013), using a loading of $60 \mathrm{FPU} / \mathrm{g}$ glucan, hemicellulase enzyme (Novozyme NS22002) at a loading of 2.5 FBG/g glucan and $\beta$-glucosidase (Novozyme NS50010) at $4.5 \mathrm{CBU} / \mathrm{g}$ glucan. Saccharomyces cerevisiae (ATCC 24858) was then inoculated into the reaction vessel to commence the SSF process.

Saccharomyces cerevisiae (ATCC 24858) was the yeast used to ferment the enzymatically-generated sugars. For ethanol production through the SSF process, $10 \mathrm{~mL}$ of seed culture was used to inoculate $200 \mathrm{~mL}$ of yeast-peptone-dextrose (YPD) broth in a $1 \mathrm{~L}$ Erlenmeyer flask. The cultures were incubated in a shaker at $30^{\circ} \mathrm{C}$ and $150 \mathrm{rpm}$ and grown aerobically overnight. The suspended yeast cultures were transferred into $50 \mathrm{~mL}$ capped centrifugation tubes, and were harvested by centrifugation at $2600 \mathrm{RCF}$ for $15 \mathrm{~min}$ at room temperature. The supernatant was discarded, and the cells were transferred into $125 \mathrm{~mL}$ 
Wheaton septum glass bottles containing $50 \mathrm{~mL}$ of pretreated hydrolyzate already inoculated with the enzymes. The bottles were then tightly capped to allow fermentation to occur largely under anaerobic conditions. The cultures were placed in a rotary shaker and incubated at $35{ }^{\circ} \mathrm{C}$ and $160 \mathrm{rpm}$. Aliquots of the fermentation broth were collected at designated times: $0,3,6,9,12,24,48$ and 72 hours. The aliquot samples were analyzed for sugars and ethanol concentrations using an HPLC. Untreated miscanthus was also taken through the same process to serve as a control and allow for comparison.

The ethanol yield was expressed as the percentage of the theoretical yield using the following formula

$$
\% \text { Yield }_{\text {ethanol }}=\left[\frac{C_{\text {ethanol, } \mathrm{f}}-C_{\text {ethanol, } \mathrm{i}}}{0.568 f . C_{\text {biomass }}}\right] \times 100 \%
$$

Where $C_{\text {ethanol, }}$ is the ethanol concentration at the end of the fermentation $(\mathrm{g} / \mathrm{L}), C_{\text {ethanol, }}$ is the ethanol concentration at the beginning of the fermentation $(\mathrm{g} / \mathrm{L}), C_{\text {biomass }}$ is the dry biomass concentration at the beginning of the fermentation $(\mathrm{g} / \mathrm{L}), f$ is the cellulose fraction of the dry biomass $(\mathrm{g} / \mathrm{g})$, and 0.568 is the conversion factor from cellulose to ethanol.

\subsection{Chemical analyses}

The elemental compositions $(\mathrm{C}, \mathrm{H}, \mathrm{N}, \mathrm{S})$ of the untreated and pretreated miscanthus were determined using a PE 2400 II CHNS/O analyzer (Perkin Elmer Japan Co., Ltd.). The oxygen content was calculated by difference: $\mathrm{O} \%=100-(\mathrm{C}+\mathrm{H}+\mathrm{N}+\mathrm{S}) \%$. The miscanthus samples were digested with $\mathrm{HNO}_{3} / \mathrm{HCl}$ in a microwave oven $\left(200{ }^{\circ} \mathrm{C}, 2 \mathrm{MPa}\right)$ and analyzed by inductively coupled plasma-optical emission spectroscopy (ICP-OES) (ARL 3560, Waltham, MA, US) for minerals. The concentration of sugar monomers (cellobiose, 
glucose, arabinose, and xylose), in all liquid fractions and ethanol were determined using a Dionex Ultimate 3000 UHPLC (Thermo Fisher Scientific, Bannockburn, IL) with a Shodex Sugar SH1281 ion exclusion column and a Shodex RI-101 refractive index detector. The mobile phase was $0.01 \mathrm{~N} \mathrm{H}_{2} \mathrm{SO}_{4}$ solution at a flow rate of $1.000 \mathrm{~mL} / \mathrm{min}$. The temperatures of the detector and column were maintained at 50 and $75{ }^{\circ} \mathrm{C}$, respectively.

\section{Results and Discussion}

3.1 Mass flow into solid and liquid fractions from mechanical pressing

Mechanical pressing effectively separated the freshly harvested miscanthus into its solid and liquid components after pressing at 30,000 lbs for $15 \mathrm{~min}$. The mass distribution was about $0.4 \mathrm{~g} / \mathrm{g}$ of solid and between 0.5 to $0.6 \mathrm{~g} / \mathrm{g}$ of liquid (Figure 1). The moisture content of giant miscanthus could be 50\% or more, depending on the time of harvest (Brosse et al., 2012). Since miscanthus was harvested in the early summer, high moisture content led to high amounts of the liquid fraction being achieved. The liquid fraction can be used for downstream processing within a biorefinery platform for the production of chemicals (Boakye-Boaten et al., 2015).

3.2 Characteristics of dry and wet processed miscanthus

The elemental and mineral compositions of the miscanthus samples are listed in Table 1 below for comparative purposes. The elemental compositions of the samples are similar and are within the ranges reported in literature. It has been previously reported that the major elemental composition of miscanthus, based on dry matter includes 47.1 to 49.7 
$\% \mathrm{C}, 5.3$ to $5.9 \% \mathrm{H}$ and 41.4 to $44.6 \% \mathrm{O}$, which somewhat reflects the variation of three major lignocellulosic components of the biomass (Brosse et al., 2012). Previous studies conducted also resulted in $46.1 \% \mathrm{C}, 41.9 \% \mathrm{O}, 7.3 \% \mathrm{H}, 1.7 \% \mathrm{~N}$ and $0.6 \% \mathrm{~S}$ (BoakyeBoaten et al., 2015). These values are consistent with the values reported in the present work.

The carbon-to-nitrogen ratio of biomass species has been identified as an important parameter for ethanol production. It has been reported that the concentration of ethanol produced from a biomass feedstock increases as carbon to nitrogen $(\mathrm{C} / \mathrm{N})$ ratios of the substrate increase, with $\mathrm{C} / \mathrm{N}$ ratio being a parameter influencing the yield of ethanol from biomass, with a linear correlation between the two parameters (Imamoglu and Sukan, 2014). The high values of carbon and the low values of $\mathrm{N}$ in the miscanthus species employed in this study gave a high C/N ratio (e.g. T1 (116.0), T5 (91.3) and Tsw (109.4)), making them prime candidates for ethanol production.

Furthermore, the concentration of $\mathrm{K}, \mathrm{Ca}, \mathrm{P}, \mathrm{Mg}$ and especially $\mathrm{Si}$ are responsible for the ash content of biomass (Lewandowski and Kicherer, 1997). The relatively higher concentrations of these minerals in the biomass could lead to higher ash content, which could be a major issue during combustion within a thermochemical platform. However, miscanthus generally has lower $\mathrm{Cl}, \mathrm{K}, \mathrm{N}, \mathrm{S}$ and ash concentrations compared to other lignocellulose plants, making them good bioenergy crops for both biochemical and thermochemical processing (Lewandowski and Kicherer, 1997).

3.3 Composition of raw and pretreated Miscanthus x giganteus 
The compositions of miscanthus before and after dilute sulfuric acid pretreatment are given in Tables 2 and 3. The composition of cellulose in the raw biomass ranged from $59.8 \%$ to $66.7 \%$ by mass (Table 2 ). There was not a significant difference in these compositions regardless of the processing method employed. Hemicellulose composition ranged from $43.0 \%$ to $49.0 \%$, with lignin ranging between 19.3 to $22.1 \%$ by mass. Miscanthus, with its cellulose content of approximately $40.0 \%$ and above, is considered useful for biofuel production (Sørensen et al., 2008). The composition of the raw miscanthus in the present study is consistent with previous findings reported so far (Brosse et al., 2009; Scordia et al., 2013), even though this study reports slightly higher hemicellulose composition.

After dilute sulfuric acid pretreatment, the composition of the biomass changed, with an increase in the cellulose and lignin contents and a decrease in the hemicellulose content the biomass samples (Table 3). The increase in the cellulose content was also significantly higher in the pretreated wet processed biomass than in the pretreated dry processed biomass (Table 3), even though the cellulose contents for both processes were still higher than that of the untreated biomass (Table 2 and 3). The dry processing of the miscanthus resulted in a fibrous, more amorphous miscanthus structure, compared to the wet processing. This amorphous structure obtained through dry processing invariably reduced the crystallinity of the miscanthus more than the wet processed sample, and from figure 1a, it can be seen that the concentration of glucose in the liquid fraction after pretreatment was higher in the dry processed miscanthus than the wet processed 
miscanthus, suggesting that the wet processed miscanthus was able to retain more of the cellulose in the solid fraction due to its greater crystallinity during the pretreatment.

In DSAP, high temperatures result in hemicellulose hydrolysis during the pretreatment, releasing monomeric sugars from the cell wall matrix into the hydrolyzate. This removal of hemicellulose increases porosity and improves enzymatic digestibility (Ballesteros et al., 2008). The pretreatment parameters (pretreatment severity) employed in this study were very effective across the board, as they resulted in almost the complete hydrolysis of the hemicellulose fraction of the biomass samples from about $46.0 \%$ in the untreated samples to approximately $1.0 \%$ in pretreated samples (Table 2 and 3). Maximum enzymatic digestibility is usually obtained as a result of the complete removal of hemicellulose (Ballesteros et al., 2008). The effectiveness of the pretreatment is further augmented by figures $2 \mathrm{a}$ and $2 \mathrm{~b}$, which shows that in the hydrolyzate, the concentration of glucose was lower (Figure 2a) compared to the concentration of xylose (Figure 2b), basically signifying the presence of more hemicellulose in the hydrolyzate than in the recovered solid fraction. Feedstocks pretreated with dilute acid have been shown to give a high recovery of hemicellulose sugars in the liquid fraction, with most of the cellulose remaining in the solid residue for sequential enzymatic hydrolysis (Hsu et al., 2010).

The increase in the lignin composition of the samples after pretreatment (Table 2 and 3) could be attributed to the increase in the porosity of the sample. Ballesteros et al (2008) observed that lignin content in cardoon (Cynara cardunculus L.) increased after dilute sulfuric acid pretreatment, with the increase occurring concomitantly with temperature or acid concentration. Generally, the lignin composition is considered to be a 
critical factor during enzymatic hydrolysis and fermentation, and it has been observed for instance in corn stover that the rearrangement of the lignin structure during dilute acid pretreatment negatively affected enzymatic saccharification (Kumar and Wyman, 2009). Hsu et al (2010), however state that the structural features of lignin vary across various feedstocks, as such the effect of lignin composition on enzymatic hydrolysis and fermentation may be different for various feedstocks.

Also it has been suggested that the hemicelluloses-lignin matrix that surrounds the cellulose fraction in the biomass act as a physical barrier, hindering the access of cellulase to the surface of the cellulose. Therefore, it is believed that removing the hemicellulose may increase the pore volume and surface area of the solid residue and thus facilitate access of cellulase to the cellulose structure (Zhu et al., 2008). Furthermore, studies of dilute acid pretreatment show that hemicellulose removal substantially enhances digestion, despite its high lignin content, and that even though the removal of hemicellulose alone increases the surface area and pore volume and makes cellulose more accessible to cellulase, acid pretreatment at high temperatures chemically modifies and recondenses lignin as an altered lignin polymer, which makes it play a less detrimental role in digestibility (Zhu et al., 2008). As such, the increase in the lignin content observed after dilute acid pretreatment would not automatically affect ethanol yield and concentration, since a myriad of factors interact to determine the effectiveness of the fermentation process.

Miscanthus samples from swine manure treated soils exhibited the most cellulose and the least amount of lignin after pretreatment. Studies have shown that, when applied 
correctly, swine manure improves the physical, chemical and biological characteristics of soils, which can affect plant quality (Segat et al., 2015).

\subsection{Morphological changes to biomass after DSAP}

Electron micrographs showing morphological features of untreated and DSAP pretreated miscanthus are provided below (Figures S1). After the pretreatment process, some changes to the morphology of the biomass were observed. These changes basically indicate the partial disruption or destruction of the biomass structure. In comparing the untreated biomass (Figures S1a and S1c) to the pretreated samples (Figures S1b and S1d), it can be clearly deduced that the untreated biomass exhibits more robust structures possibly made up of hemicellulase, lignin, and other binding material. DSAP led to the breakdown of this robust structure. A careful look at the pretreated samples (Figures S1b and S1d) indicates that the pretreatment succeeded in exposing the internal structure and fibers of the biomass (Saini et al., 2013). Furthermore, the rigidity of the cellulose fibers appeared to have been lost, becoming distorted after the pretreatment. In comparing the images of the pretreated dry processing sample (Figure S1b) to the pretreated wet processing sample (Figure S1d), the pretreated wet samples show a greater degree of distortion than the pretreated dry processing samples, and this could be attributed to the higher amount of cellulose observed in the pretreated wet processing samples than in the dry processing samples.

\subsection{FT-IR spectra analysis}


The spectrum of raw, wet- and dry-processed miscanthus in figure S2a, shows identical peaks for both samples before pretreatment. The polysaccharides (hemicellulose and cellulose) peaks are around 898, 1094, 1127, 1172, 1200, 1325 and $1374 \mathrm{~cm}^{-1}$, whiles the lignin peaks are around 1253 and $1514 \mathrm{~cm}^{-1}$. The peaks around $1734 \mathrm{~cm}^{-1}$, correspond to ester-linked acetyl, feruloyl and p-coumaroyl groups between hemicellulose and lignin (Wang et al., 2010).

After pretreatment, the polysaccharide peaks became sharper and their heights were increased quite dramatically - an indication of increasing polysaccharides, especially cellulose - since the composition of hemicellulose in the biomass was drastically decreased. Furthermore, after the pretreatment, peak $1734 \mathrm{~cm}^{-1}$ was reduced greatly in both the dry and wet processed samples (figure S2b and S2c). The peak represents ester-linked acetyl, feruloyl and p-coumaroyl groups between hemicellulose and lignin, and its reduction is an indication of the removal of hemicellulose from the biomass. The polysaccharide peak around $898 \mathrm{~cm}^{-1}$, increased in intensity and height, a good indication of increasing cellulose composition after pretreatment.

3.6 Simultaneous saccharification and fermentation, ethanol concentration and yield After 72 hours of simultaneous saccharification and fermentation using saccharomyces cerevisiae and a cocktail of enzymes at $35^{\circ} \mathrm{C}$, the ethanol concentration varied among the samples. The highest concentration of $0.7 \mathrm{~g} / 100 \mathrm{ml}$ over the 72 -hour period was observed for the biomass sample grown with swine manure, wet processed and pretreated (Tsw-wet) (Figure 3a). The figure also shows that in all cases, the ethanol 
concentration was higher for the wet processed samples than the dry processed samples. This augments the observation made after the DSAP, where the cellulose composition of the wet processed samples increased more than the dry processed samples after pretreatment, even though they were comparable before the pretreatment.

Apart from the energy efficiency concerns of conventional bioethanol production, which involves drying, (sometimes at high temperatures) the application of heat during biomass sample preparation can be considered a form of heat stress, which, beyond a certain threshold, can induce irreversible damage to the plant cell walls, possibly changing the composition (Le Gall et al., 2015). Application of constantly high temperatures causes a range of morpho-anatomical, physiological and biochemical changes in plant cell walls (Le Gall et al., 2015). Changes could have occurred to the dry processed miscanthus samples treated at $105^{\circ} \mathrm{C}$, which resulted in lower ethanol concentrations observed during the fermentation process.

The ethanol concentration between the wet processed samples is compared in figure $3 b$, which shows that during the SSF process, miscanthus grown with swine manure consistently exhibited higher ethanol concentrations. The time series of ethanol production depicted by figure 5a for pretreated Tsw sample shows that from hour 0 to 24 , there was rapid production of ethanol, while the concentration of glucose reduced rapidly as well, with the measured xylose concentration remaining stable throughout the period. This trend was evident in the other samples as well (Figure 4b). The production of ethanol began to level off during the following 72 hours, with a continued reduction in glucose and a consistent xylose concentration. 
The rapid production of ethanol in the first 24 hours can be attributed to a number of factors, including enhanced hydrolysis due to the use of a blend, or "cocktail" of enzymes. Cellulase is aggressive in degrading cellulose into fermentable sugars and betaglucosidase can reduce cellobiose inhibition during SSF by converting cellobiose into glucose, leading to increased hydrolysis (Boonsawang et al., 2012). This likely produced enough sugar initially for the fermenting organism to metabolize into ethanol.

Furthermore, the low substrate concentration and supplemental beta-glucosidase employed helped reduce end-product inhibition by glucose and cellobiose during SSF (Zhu et al., 2008).

When enzyme diffusion and product inhibition are eliminated at low substrate concentrations, enzymatic hydrolysis of biomass solely depends on enzyme accessibility and efficiency, which are inextricably linked to biomass structural features (Zhu et al., 2008). As such, the effectiveness of the pretreatment employed likely altered both the chemical (cellulose, hemicellulose, lignin) and the physical structural features (surface area, crystallinity, physical distribution of lignin matrix, degree of polymerization, pore volume and biomass particle size) of the biomass, thus enhancing ethanol production (Zhu et al., 2008). The $\mathrm{pH}$ of 4.5 for the process also creates a conducive environment for the SSF reaction, as a $\mathrm{pH}$ range of 4.0-5.0 is regarded as the operational limit for the anaerobic ethanol production process (Lin et al., 2012).

The use of saccharomyces cerevisiae could also be considered to have contributed to the ethanol concentration observed. S. cerevisiae produces ethanol with stoichiometric yields from hexose sugars such as glucose, mannose and galactose (Fernandes and Murray, 
2010). The rapid release of glucose during hydrolysis aided the rapid ethanol production observed within the first 24 hours. A similar observation was made during the fermentation of alfalfa for ethanol production (Shuangning et al., 2014). As expected, since saccharomyces cerevisiae does not metabolize pentose sugars such as xylose, the xylose concentration remained unchanged over the period (Fernandes and Murray, 2010).

During batch fermentation, the rate of ethanol produced per milligram of cell protein is maximal for a brief period early in the process and declines progressively as ethanol accumulates in the surrounding broth (Dombek and Ingram, 1987). This can be observed in the time series graphs (Figures $4 \mathrm{a}$ and $4 \mathrm{~b}$ ) where, after 24 hours, there was a progressive decrease in the ethanol concentration even as glucose concentration also decreased. This decline in the metabolic rate of viable yeast cells is due in part to physiological changes (including possible ethanol damage), where the exposure of cells to ethanol in some way damages their ability to produce ethanol, with the extent of damage related to both ethanol concentration and the duration of exposure (Dombek and Ingram, 1987). Ethanol concentrations over time for wet and dry processed samples showed the same trends discussed above, and further showed that in all cases, the ethanol concentrations were higher over the period for the wet processed biomass than the dry processed biomass, most likely due to reasons also discussed above, including heat damage to the biomass during drying.

The theoretical ethanol yield was calculated according to equation 1. Figure 5 shows the ethanol yield calculated for the wet and dry processed miscanthus. Just as the cellulose fraction in the biomass after pretreatment was higher in the wet processed 
samples than the dry processed samples, and just as ethanol concentrations measured during SSF were also higher for the wet samples than the dry samples, the theoretical ethanol yield was higher for the wet processed pretreated samples than the dry processed pretreated samples, with the highest theoretical ethanol yield of $88.4 \%$ recorded for miscanthus fertilized with swine manure. These ethanol yields are consistent with values expressed in the literature for miscanthus. Thermotolerant yeast was used for bioethanol production using miscanthus, with an $86.3 \%$ theoretical ethanol yield observed (Cha et al., 2015). The maximum theoretical ethanol yield for alkali-pretreated miscanthus has been reported at $67.0 \%$ (Kang et al., 2013). A maximum theoretical ethanol yield of $75.0 \%$ was also observed for oxalic acid pretreated miscanthus (Scordia et al., 2013).

\section{Conclusions}

After dilute acid pretreatment, wet processed samples performed better than the dry in producing bioethanol through SSF using yeasts. Glucan content was higher in the wet samples after pretreatment than the dry samples, resulting in higher hydrolysis rates and ethanol concentrations and yields. This work is an indication of how the energy efficiency of bioethanol processing can be improved within a biorefinery platform, to make it more competitive with the petroleum refinery industry.

\section{Acknowledgment}

The authors are grateful for the support of the USDA-CSREES-Evans-Allen 
Project, Grant No. NCX-272-5-13-130-1. We are also grateful to Bryce Holmes, Matt

Miller, Alex Aboagye, Richard Abrokwah, John Eshun, Jada Oates, Quazi Rahman and

Taylor Butler, all of North Carolina A \& T State University, for the various roles they

played in getting this work done.

\section{References}

1. Bai, F.W., Anderson, W.A., Moo-Young, M., 2008. Ethanol fermentation technologies from sugar and starch feedstocks. Biotechnol. Adv. 26, 89-105.

2. Ballesteros, I., Ballesteros, M., Manzanares, P., Negro, M.J., Oliva, J.M., Sáez, F., 2008. Dilute sulfuric acid pretreatment of cardoon for ethanol production. Biochem. Eng. J. 42, 84-91.

3. Boakye-Boaten, N.A., Xiu, S., Abolghasem, S., Fabish, J., 2015. Liquid Hot Water Pretreatment of Miscanthus x. Giganteus for the Sustainable Production of Bioethanol. BioResources 10, 5890-5905.

4. Boonsawang, P., Subkaree, Y., Srinorakutara, T., 2012. Ethanol production from palm pressed fiber by prehydrolysis prior to simultaneous saccharification and fermentation (SSF). Biomass Bioenergy 40, 127-132.

5. Brosse, N., Dufour, A., Meng, X., Sun, Q., Ragauskas, A., 2012. Miscanthus: a fastgrowing crop for biofuels and chemicals production. Biofuels, Bioprod. Bioref.

6. Brosse, N., Sannigrahi, P., Ragauskas, A., 2009. Pretreatment of Miscanthus x giganteus Using the Ethanol Organosolv Process for Ethanol Production. Ind. Eng. Chem. Res. 48, 8328-8334.

7. Cha, Y.-L., An, G.H., Yang, J., Moon, Y.-H., Yu, G.-D., Ahn, J.-W., 2015. Bioethanol production from Miscanthus using thermotolerant Saccharomyces cerevisiae mbc 2 isolated from the respiration-deficient mutants. Renew. Energy 80, 259-265.

8. Choi, C.H., Kim, J.S., Oh, K.K., 2013. Evaluation the efficacy of extrusion pretreatment via enzymatic digestibility and simultaneous saccharification \& fermentation with rapeseed straw. Biomass Bioenergy 54, 211-218.

9. Christian, D.G., Riche, A.B., Yates, N.E., 2008. Growth, yield and mineral content of Miscanthus $\times$ giganteus grown as a biofuel for 14 successive harvests. Ind. Crops Prod. 28, 320-327.

10. Dombek, K., Ingram, L., 1987. Ethanol Production during Batch Fermentation with Saccharomyces cerevisiae: Changes in Glycolytic Enzymes and Internal pH. Appl. Environ. Microbiol. 53, 1286-1291.

11. Eliana, C., Jorge, R., Juan, P., Luis, R., 2014. Effects of the pretreatment method on enzymatic hydrolysis and ethanol fermentability of the cellulosic fraction from elephant grass. Fuel 118, 41-47. 
12. Fennell, L.P., Boldor, D., 2014. Continuous microwave drying of sweet sorghum bagasse biomass. Biomass Bioenergy 70, 542-552.

13. Fernandes, S., Murray, P., 2010. Metabolic engineering for improved microbial pentose fermentation. Bioeng. Bugs 1, 424-428.

14. Ferrari, M.D., Guigou, M., Lareo, C., 2013. Energy consumption evaluation of fuel bioethanol production from sweet potato. Bioresour. Technol. 136, 377-384.

15. Hsu, T.-C., Guo, G.-L., Chen, W.-H., Hwang, W.-S., 2010. Effect of dilute acid pretreatment of rice straw on structural properties and enzymatic hydrolysis. Bioresour. Technol., Special Issue on Lignocellulosic Bioethanol: Current Status and Perspectives 101, 4907-4913.

16. Imamoglu, E., Sukan, F.V., 2014. The effects of single and combined cellulosic agrowaste substrates on bioethanol production. Fuel 134, 477-484.

17. Kang, K.E., Han, M., Moon, S.-K., Kang, H.-W., Kim, Y., Cha, Y.-L., Choi, G.-W., 2013. Optimization of alkali-extrusion pretreatment with twin-screw for bioethanol production from Miscanthus. Fuel 109, 520-526.

18. Kärcher, M.A., Iqbal, Y., Lewandowski, I., Senn, T., 2015. Comparing the performance of Miscanthus $\mathrm{x}$ giganteus and wheat straw biomass in sulfuric acid based pretreatment. Bioresour. Technol. 180, 360-364.

19. Kumar, R., Wyman, C.E., 2009. Cellulase adsorption and relationship to features of corn stover solids produced by leading pretreatments. Biotechnol. Bioeng. 103, 252-267.

20. Le Gall, H., Philippe, F., Domon, J.-M., Gillet, F., Pelloux, J., Rayon, C., 2015. Cell Wall Metabolism in Response to Abiotic Stress. Plants 4, 112-166.

21. Lewandowski, I., Kicherer, A., 1997. Combustion quality of biomass: practical relevance and experiments to modify the biomass quality of Miscanthus $\mathrm{x}$ giganteus. Eur. J. Agron. 6, 163-177.

22. Lin, Y., Zhang, W., Li, C., Sakakibara, K., Tanaka, S., Kong, H., 2012. Factors affecting ethanol fermentation using Saccharomyces cerevisiae BY4742. Biomass Bioenergy 47, 395-401.

23. Nghiem, N.P., Ramírez, E.C., McAloon, A.J., Yee, W., Johnston, D.B., Hicks, K.B., 2011. Economic analysis of fuel ethanol production from winter hulled barley by the EDGE (Enhanced Dry Grind Enzymatic) process. Bioresour. Technol. 102, 6696-6701.

24. Pfeffer, M., Wukovits, W., Beckmann, G., Friedl, A., 2007. Analysis and decrease of the energy demand of bioethanol-production by process integration. Appl. Therm. Eng., Selected Papers from the 9th Conference on Process Integration, Modelling and Optimisation for Energy Saving and Pollution Reduction - PRES2006 27, 2657-2664.

25. Saha, B.C., Nichols, N.N., Qureshi, N., Kennedy, G.J., Iten, L.B., Cotta, M.A., 2015. Pilot scale conversion of wheat straw to ethanol via simultaneous saccharification and fermentation. Bioresour. Technol. 175, 17-22.

26. Saini, J.K., Anurag, R.K., Arya, A., Kumbhar, B.K., Tewari, L., 2013. Optimization of saccharification of sweet sorghum bagasse using response surface methodology. Ind. Crops Prod. 44, 211-219. 
27. Scordia, D., Cosentino, S.L., Jeffries, T.W., 2013. Effectiveness of dilute oxalic acid pretreatment of Miscanthus $\times$ giganteus biomass for ethanol production. Biomass Bioenergy 59, 540-548.

28. Segat, J.C., Alves, P.R.L., Baretta, D., Cardoso, E.J.B.N., 2015. Ecotoxicological evaluation of swine manure disposal on tropical soils in Brazil. Ecotoxicol. Environ. Saf. 122, 91-97.

29. Shuangning, X., Shahbazi, A., Boakye-Boaten, N.A., 2014. Effects of Fractionation Methods on the Isolation of Fiber-rich Cake from Alfalfa and Ethanol Production from the Cake. BioResources 9, 3407-3416.

30. Silva Ortiz, P., de Oliveira Jr., S., 2014. Exergy analysis of pretreatment processes of bioethanol production based on sugarcane bagasse. Energy 76, 130-138.

31. Sluiter, A., Hames, B., Ruiz, R., Scarlata, C., Sluiter, J., Templeton, D., 2008. Determination of Ash in Biomass.

32. Sluiter, A., Hames, B., Ruiz, R., Scarlata, J., Sluiter, J., Templeton, D., Christian, D., 2011. Determination of Structural Carbohydrates and Lignin in Biomass.

33. Sørensen, A., Teller, P.J., Hilstrøm, T., Ahring, B.K., 2008. Hydrolysis of Miscanthus for bioethanol production using dilute acid presoaking combined with wet explosion pre-treatment and enzymatic treatment. Bioresour. Technol. 99, 66026607.

34. Wang, B., Wang, X., Feng, H., 2010. Deconstructing recalcitrant Miscanthus with alkaline peroxide and electrolyzed water. Bioresour. Technol. 101, 752-760.

35. Zhu, L., O’Dwyer, J.P., Chang, V.S., Granda, C.B., Holtzapple, M.T., 2008. Structural features affecting biomass enzymatic digestibility. Bioresour. Technol. 99, 38173828 . 


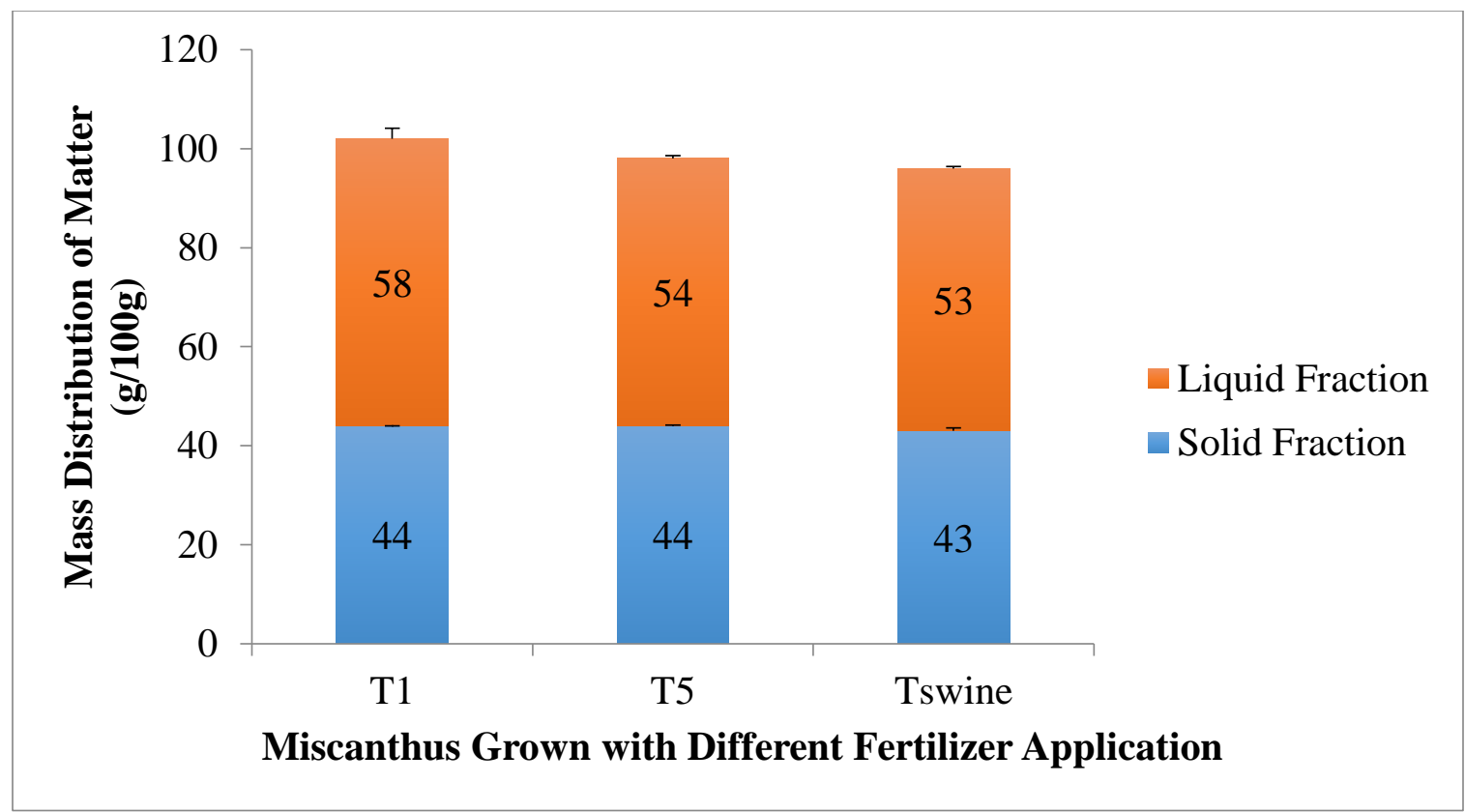

Figure 1: Mass distribution of miscanthus into solid and liquid fraction from mechanical pressing. 


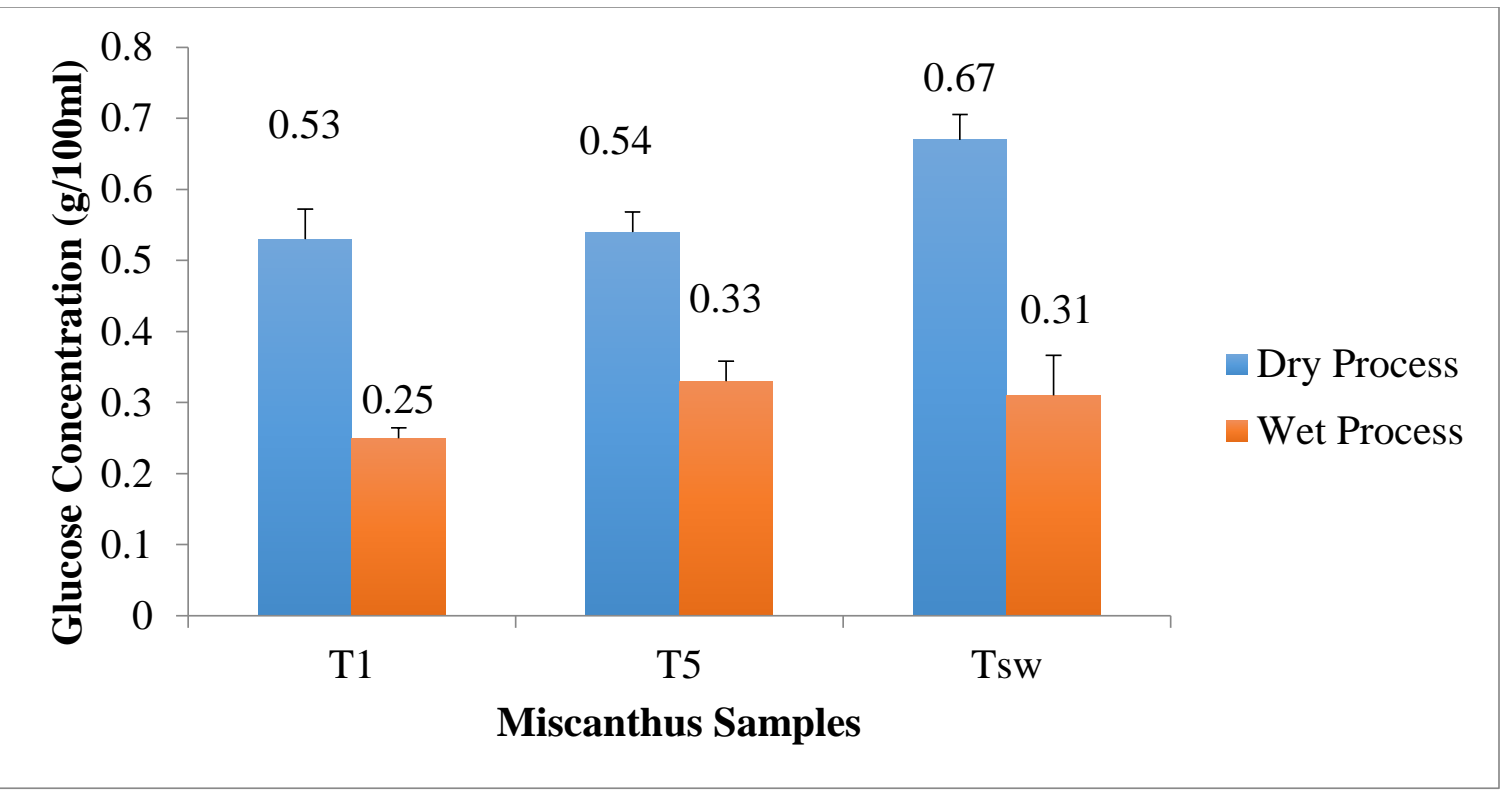

(a)

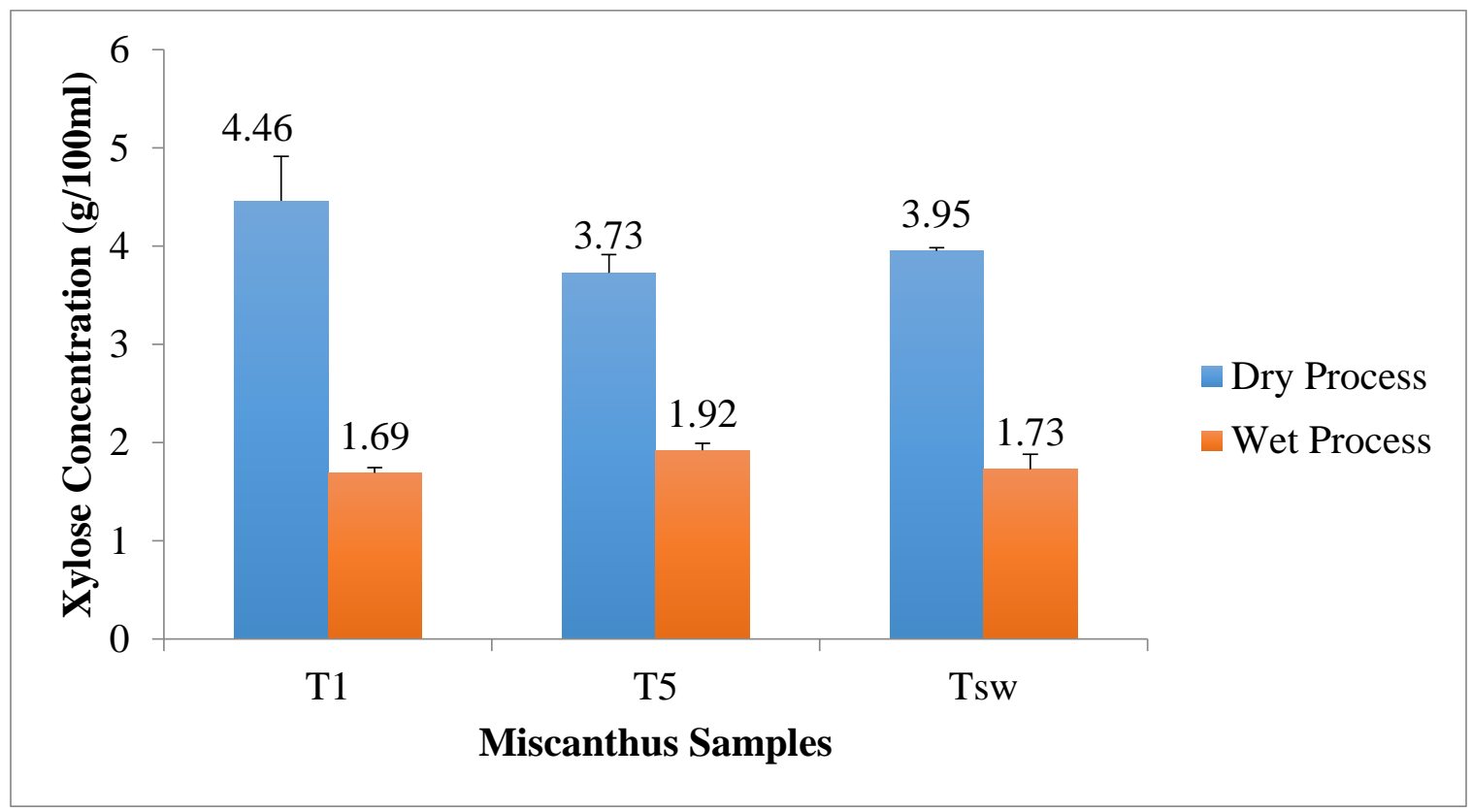

(b)

Figure 2. Glucose (a) and Xylose (b) concentration of DSAP hydrolysate 


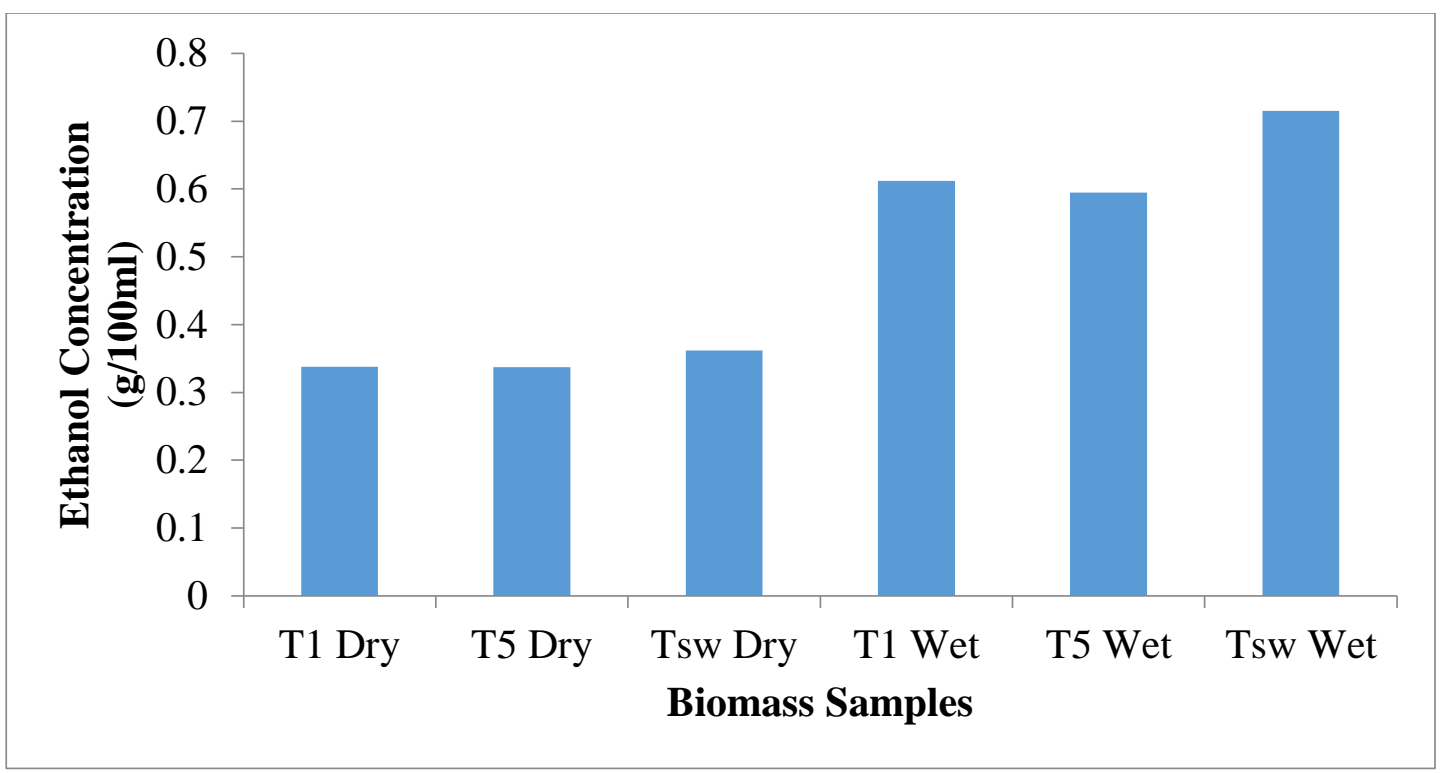

(a)

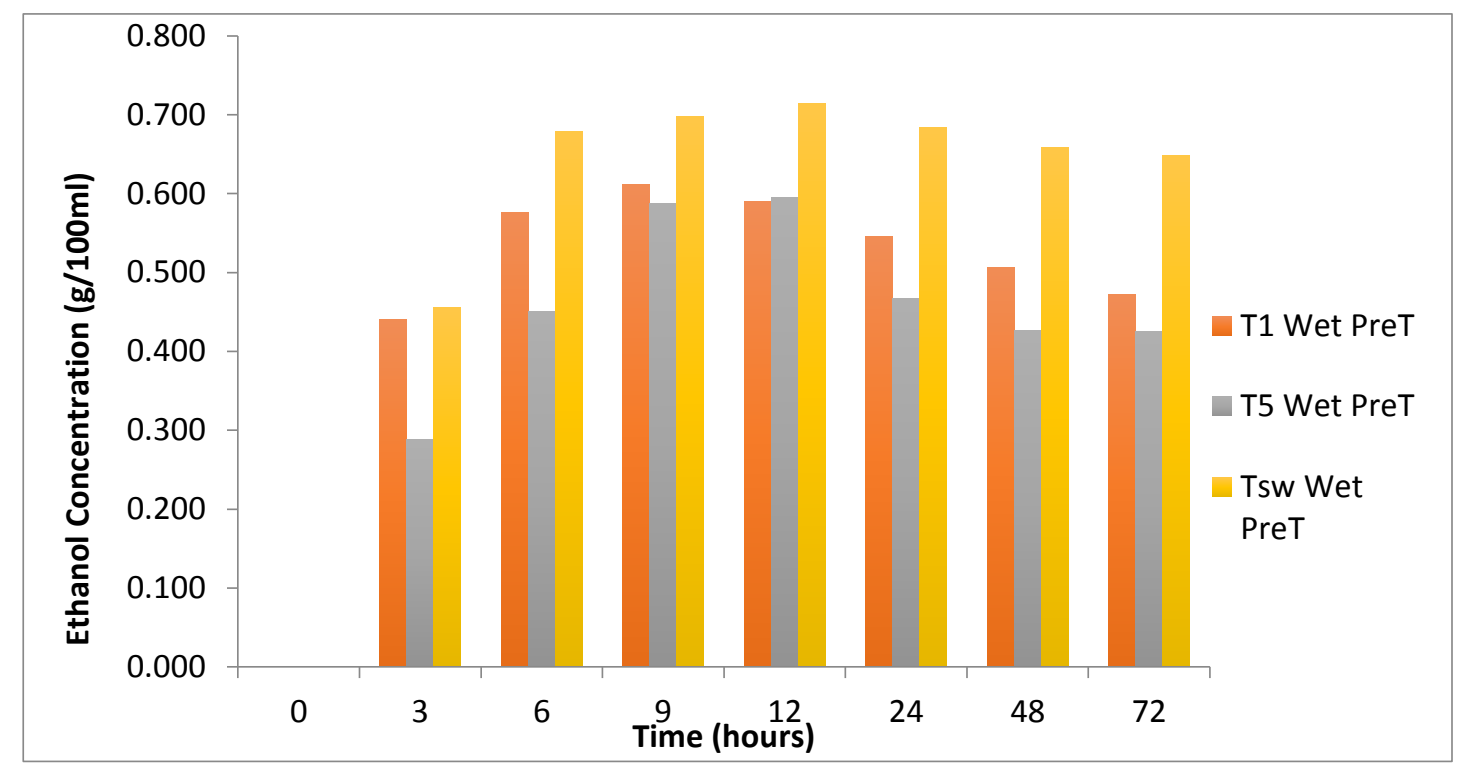

(b)

Figure 3. Ethanol Concentration of Miscanthus Samples. (a) Pretreated Miscanthus samples; (b) wet processed $\mathrm{MxG}$ 


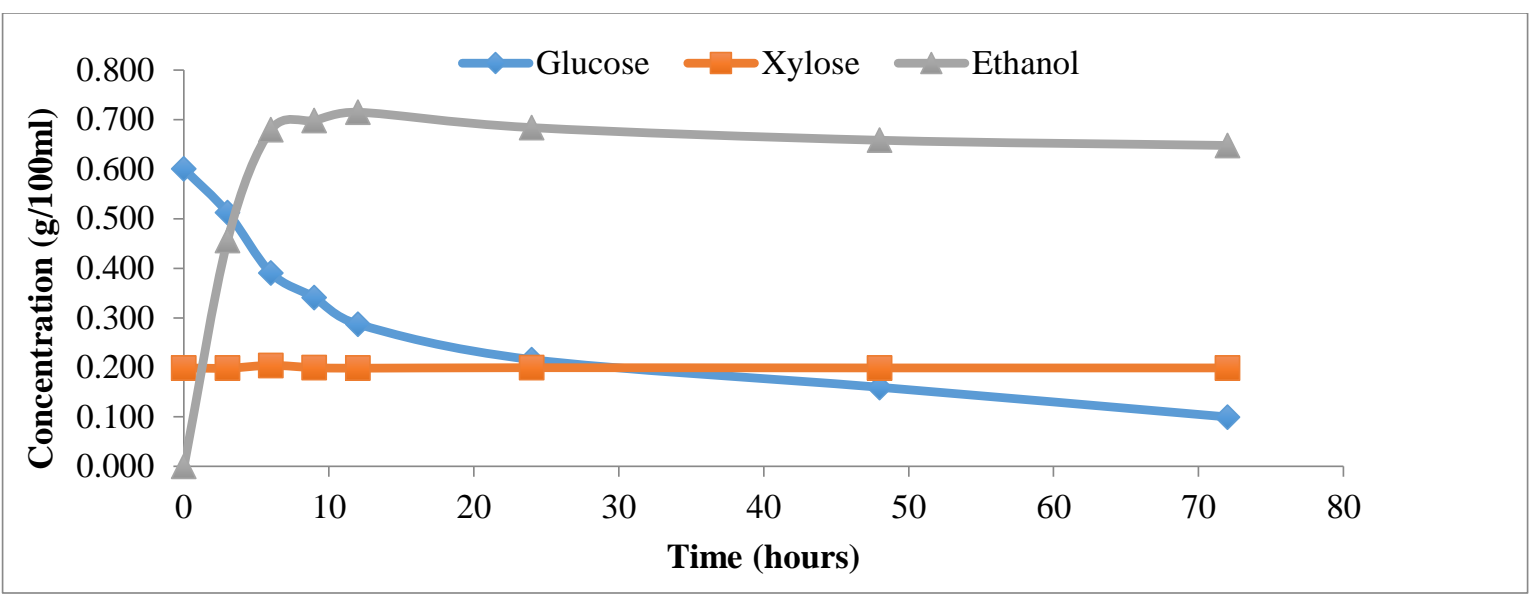

(a)

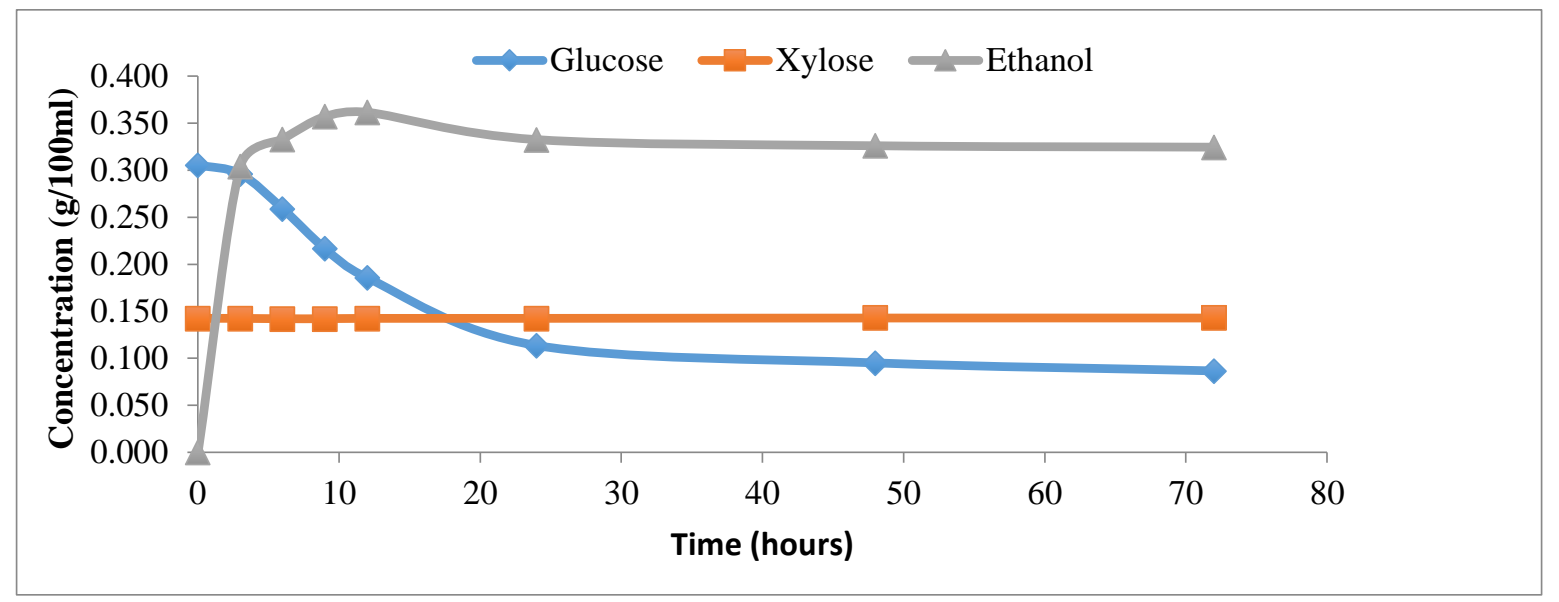

(b)

Figure 4. Time Series Depiction of Ethanol Production. (a) Tsw pretreated wet sample fermentation; (b) Tsw pretreated dry sample fermentation 


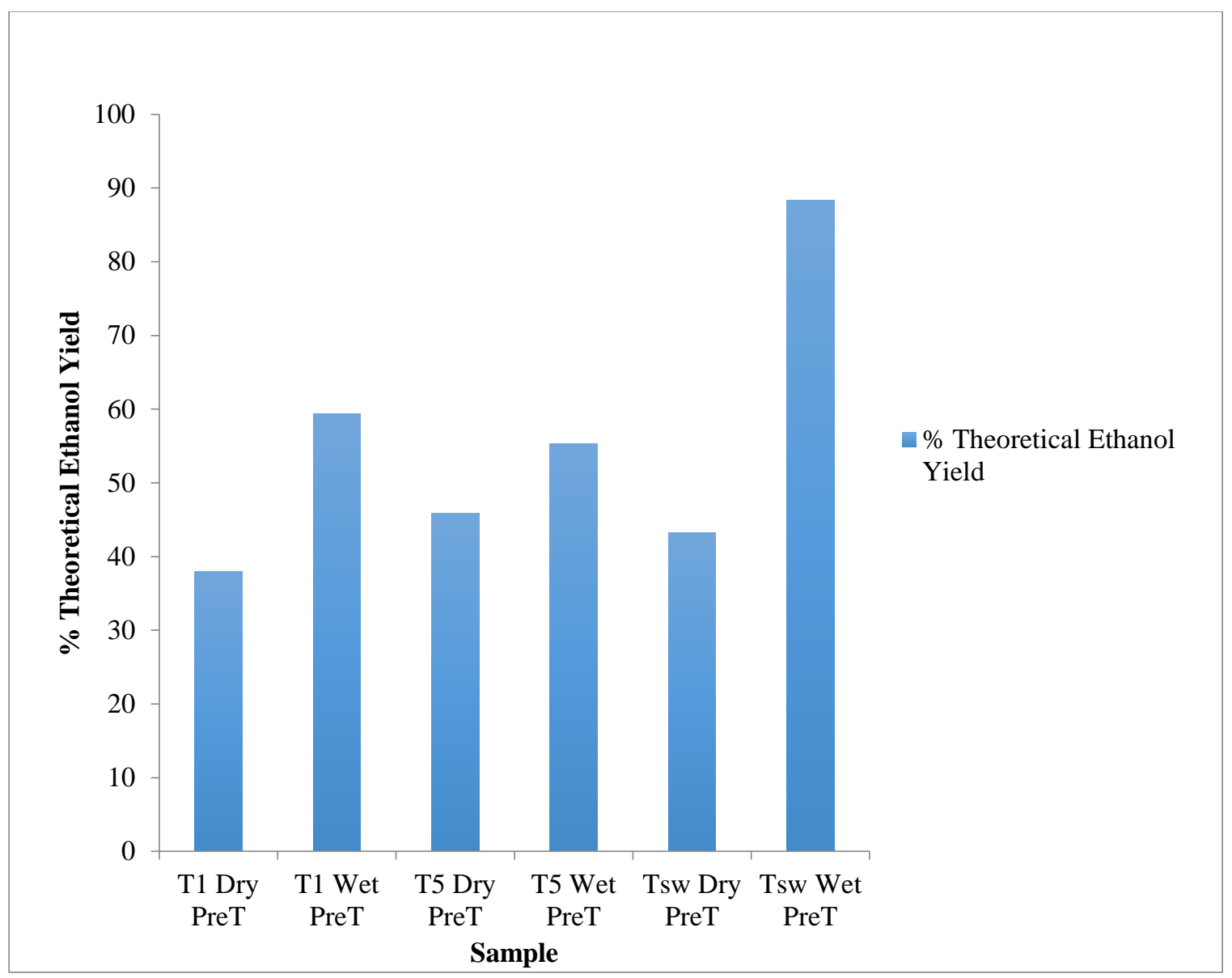

Figure 5. Percent theoretical ethanol yield of different miscanthus samples. 
Table 1

Elemental and Mineral Compositions of Miscanthus

\begin{tabular}{|c|c|c|c|c|c|c|}
\hline $\begin{array}{l}\text { Group } \\
\text { Compositions }\end{array}$ & $\begin{array}{l}\text { T1 (Dry } \\
\text { Process) }\end{array}$ & $\begin{array}{l}\text { T5 (Dry } \\
\text { Process) }\end{array}$ & \begin{tabular}{|l} 
Tsw (Dry \\
Process) \\
\end{tabular} & $\begin{array}{l}\text { T1 (Wet } \\
\text { Process) }\end{array}$ & $\begin{array}{l}\text { T5 (Wet } \\
\text { Process) }\end{array}$ & $\begin{array}{l}\text { Tsw (Wet } \\
\text { Process) }\end{array}$ \\
\hline \multicolumn{7}{|c|}{ Elemental Composition (\%) } \\
\hline $\mathrm{C}$ & 48.2 & 48.3 & 48.19 & 48.73 & 48.37 & 47.04 \\
\hline $\mathrm{H}$ & 6.57 & 6.45 & 6.44 & 6.57 & 6.44 & 6.53 \\
\hline $\mathrm{N}$ & 0.44 & 0.59 & 0.46 & 0.42 & 0.53 & 0.43 \\
\hline $\mathrm{S}$ & 0.48 & 0.46 & 0.63 & 0.56 & 0.55 & 0.47 \\
\hline $\mathrm{O}$ & 44.34 & 44.22 & 44.3 & 43.72 & 44.11 & 45.53 \\
\hline C/N Ratio & 100.41 & 81.86 & 104.76 & 116.02 & 91.27 & 109.40 \\
\hline \multicolumn{7}{|c|}{ Mineral Composition (ppm) } \\
\hline $\mathrm{Al}$ & 21.34 & 28.55 & 29.2 & 36.88 & 22.62 & 28.49 \\
\hline B & 52.01 & 85.08 & 85.97 & 86.88 & 85.23 & 97.11 \\
\hline $\mathrm{Ca}$ & 412.33 & 378.07 & 361.95 & 488.09 & 431.67 & 447.42 \\
\hline $\mathrm{Cd}$ & 2.66 & 3.55 & 2.62 & 5.17 & 5.57 & 6.15 \\
\hline $\mathrm{Cr}$ & 37.94 & 32.09 & 26.53 & 39.65 & 31.64 & 9.97 \\
\hline $\mathrm{Cu}$ & 25.05 & 29.52 & 29.27 & 715.24 & 17.03 & 31.56 \\
\hline $\mathrm{Fe}$ & 97.43 & 144.53 & 103.84 & 130.76 & 178.91 & 52.96 \\
\hline $\mathrm{K}$ & 5506.63 & 4778.41 & 4554.41 & 6600.34 & 8462.65 & 7453.09 \\
\hline $\mathrm{Mg}$ & 1901.27 & 1288.55 & 2241.54 & 2164.77 & 1763.45 & 3125 \\
\hline $\mathrm{Mn}$ & 30.75 & 39.43 & 94.43 & 58.64 & 48.26 & 115.83 \\
\hline $\mathrm{Na}$ & 1301 & 1211.69 & 1554.2 & 163.26 & 354.65 & 487.06 \\
\hline $\mathrm{Ni}$ & 7.46 & 8.36 & 3.82 & 2.93 & 5.6 & 3.97 \\
\hline $\mathrm{P}$ & 84.2 & 63.4 & 73.7 & 89.06 & 92.33 & 118.73 \\
\hline $\mathrm{Pb}$ & 7.02 & 5.36 & 7.42 & 7.04 & 5.77 & 7.21 \\
\hline S & 11.02 & 10.56 & 12.01 & 13.7 & 13.47 & 11.29 \\
\hline $\mathrm{Zn}$ & 22.93 & 25.56 & 16.68 & 20.61 & 23.87 & 18.88 \\
\hline $\mathrm{Si}(\mathrm{g} / \mathrm{ml})$ & 2926.35 & 2517.11 & 1357.19 & 801.7 & 750.06 & 448.16 \\
\hline $\operatorname{Mo}(\mathrm{g} / \mathrm{ml})$ & 11.45 & 19.42 & 12.3 & 17.24 & 14.17 & 15.5 \\
\hline $\mathrm{Ba}$ & BDL & BDL & BDL & $\mathrm{BDL}$ & $\mathrm{BDL}$ & 0 \\
\hline $\mathrm{Sr}$ & BDL & 0.01 & BDL & $\mathrm{BDL}$ & BDL & BDL \\
\hline
\end{tabular}

BDL: Below Detection Limit 
Table 2

Composition of Raw Miscanthus

\begin{tabular}{lccc}
\hline Processing & T1 & T5 & Tsw \\
\hline Dry Processing & & & \\
\hline Cellulose $(\%$ by mass) & $63.71 \pm 8.41$ & $59.79 \pm 0.28$ & $66.11 \pm 0.17$ \\
\hline Lignin (\% by mass) & $22.05 \pm 2.52$ & $20.8 \pm 0.18$ & $20.43 \pm 0.85$ \\
\hline Ash (\% by mass) & $1.84 \pm 0.05$ & $1.49 \pm 0.12$ & $1.23 \pm 018$ \\
\hline Wet Processing & & & \\
\hline Cellulose (\% by mass) & $66.75 \pm 1.66$ & $64.4 \pm 1.65$ & $61.48 \pm 2.07$ \\
\hline Hemicellulose $(\%$ by mass) & $46.57 \pm 2.84$ & $44.85 \pm 1.63$ & $46.58 \pm 1.22$ \\
\hline Lignin (\% by mass) & $19.26 \pm 0.36$ & $21.47 \pm 0.01$ & $21.95 \pm 0.65$ \\
\hline Ash (\% by mass) & $1.92 \pm 0.12$ & $0.97 \pm 0.43$ & $1.52 \pm 0.19$ \\
\hline
\end{tabular}

Table 3

Composition of Miscanthus after dilute sulfuric acid pretreatment

\begin{tabular}{|c|c|c|c|}
\hline Processing & $\mathrm{T} 1$ & T5 & Tsw \\
\hline \multicolumn{4}{|l|}{ Dry Processing } \\
\hline Cellulose (\% by mass) & $74.95 \pm 7.55$ & $76.58 \pm 1.82$ & $71.80 \pm 1.54$ \\
\hline Hemicellulose ( $\%$ by mass) & $1.00 \pm 0.35$ & $1.03 \pm 0.00$ & $1.27 \pm 0.74$ \\
\hline Lignin (\% by mass) & $28.99 \pm 1.07$ & $28.48 \pm 1.18$ & $26.83 \pm 0.79$ \\
\hline Ash (\% by mass) & $3.40 \pm 0.31$ & $1.51 \pm 1.67$ & $0.52 \pm 0.49$ \\
\hline \multicolumn{4}{|l|}{ Wet Processing } \\
\hline Cellulose (\% by mass) & $77.06 \pm 1.93$ & $84.83 \pm 5.54$ & $87.11 \pm 0.59$ \\
\hline Hemicellulose (\% by mass) & $1.86 \pm 0.30$ & $1.64 \pm 0.49$ & $1.28 \pm 0.09$ \\
\hline Lignin (\% by mass) & $27.24 \pm 0.90$ & $25.89 \pm 0.12$ & $21.72 \pm 1.29$ \\
\hline Ash (\% by mass) & $3.15 \pm 0.21$ & $2.22 \pm 0.07$ & $1.84 \pm 0.19$ \\
\hline
\end{tabular}

